\title{
Partisan Political Participation and Ethical Moral-Self in Face of Political Corruption: Exposing Psychology of Poverty
}

\author{
Chiedozie Okechukwu Okafor ${ }^{1 *}$, Nanji Rimdan Umoh ${ }^{2}$, Uzochukwu C. Chinweze ${ }^{3}$
}

${ }^{1}$ Ph.D, Department of Psychology, Alex Ekwueme Federal University, Ndufu-Alike, Ebonyi State, Nigeria

${ }^{2} \mathrm{Ph} . \mathrm{D}$, Department of Political Science, University of Jos, Nigeria

${ }^{3}$ Ph.D, Social Science Unit, School of General Studies, University of Nigeria, Enugu Campus, Nigeria

DOI: $10.36347 /$ sjahss.2020.v08i12.002

| Received: 14.12.2020 | Accepted: 23.12.2020 | Published: 30.12.2020

*Corresponding author: Chiedozie Okechukwu Okafor

Abstract

In Nigeria, citizens negate moral values by acts of political disengagement which reflect a retrogressed sense of personal responsibility to nationhood owing to perceived corruption. We argue that both the leaders and the led, reinforce these undemocratic behaviors rather than challenge them collectively and individually. Our position therefore is that the participation or non-participation of individuals in Nigerian party politics is a function of moral confusion whereby the individual is unable to decipher right from wrong but depends on real or imagined hunger and or resource-backed signals from others to act. Data collection using Political Participation Scale and Ethical Moral Self Inventory, and data analyses using Pearson Correlation yielded significant negative correlation between ethical moral self and partisan political participation, $\mathrm{p}<.05$. The results were discussed in terms of their relevance in building strong political institutions in Nigeria and Africa in general.

Keywords: Ethics; Democracy; Moral self; Nigeria; Partisan Political participation.

Copyright $\odot 2020$ The Author(s): This is an open-access article distributed under the terms of the Creative Commons Attribution 4.0 International License (CC BY-NC 4.0) which permits unrestricted use, distribution, and reproduction in any medium for non-commercial use provided the original author and source are credited.

\section{INTRODUCTION}

Political theorists opine that all individuals ought to have an appropriate, equal opportunity to influence decision-making processes [1]. Lamprianou [2] argued that participation in political decisions in the public sphere is a more desirable form of political participation indicative of the sustainability of any democratic system. Conventional forms of participation are in themselves more structured and morally lawful, encompassing political party membership, voting, lobbying, campaigning and all other forms of political participation. However, electoral turnout and voting, which are also cornerstones of democratic political participation, have decreased over the last two decades in all parts of the world [3]. Contrariwise, the unconventional forms as described by Bourne [4] span protests, demonstrations, barricading a community, firing at the security forces, blogging and using the social media. Marsh [5] described these activities as "elite-challenging", but not necessarily illegal or unlawful. The political suspicion expressed by the teeming population against the evidently self-serving elites may underlie the preference for the unconventional-confrontational modes of participation over the more conventional practices including voter turnout. Warren [6] stated that the relationship between democracy and corruption can be described as inclusion versus exclusion. Exclusion undermines the principalagent relation and the impact and power of the people to vote and participate meaningfully. This form of corruption "corrodes the norms, processes and mechanisms of democracy itself" [6]. Its inherently bad nature reverberates in the bypass of representation, debate, and public choice [7] and a deviation from core democratic values reflective of political corruption which reduces responsiveness and frustrates the processes of deliberation.

Democracy enables inclusion and creates opportunities for those who are potentially affected by decisions to influence the decision-making processes. Verba, Schlozman and Brady [8] described the Civic Voluntarism Model (CVM) as a striking 3-dimensional model of political participation. The model evaluates the decisions of individuals not to participate in politics vis-à-vis reasons why they do. The first dimension of the CVM explains political inactivity, apathy or docility as determined by resources of time, money and civic skills. In other words, people may be politically inactive as a result of indifference despite their financial capability, the constraints posed by the lack of resources to shoulder the costs of participation, the lack of psychological engagement with politics or the lack of 
access to the recruitment networks that bring people into politics [8].

The second dimension in the model refers to engagement. It is a scenario which describes different psychological predispositions including political interest, civic values, group consciousness, and party identification. Citizens with high levels of engagement display high levels of participation. One key feature of the Civic Voluntarism Model is the interdependency between the dimensions, particularly these first two. Without the actual resources to participate, the likeliness to do so is limited. However, an individual with a lack of engagement is less likely to do so even if he or she has the resources. The third dimension is recruitment and the requests to participate which can motivate political participation. Although this third dimension is rather downplayed in the model [9], the role of various institutions such as parties, organizations, church and work-place is proven to serve as a mobilizing force for the political participant. In essence, the absence of an external influence to participate makes the individual less likely to do so despite the availability of resources and the capacity for engagement [8].

In Nigeria, the most prominent limiting factor of progressive political participation is the "psychology of poverty", defined in terms of the lack of financial confidence to withstand the temptations and intimidations of "the politics of money bags" [10]. Obviously, voter turnout is more dependent on civic skill, civic value and political interest. Observation of the 2019 general elections across various states in Nigeria shows is that voter turnout in Nigeria's general elections is becoming significant regardless of civic value, skill and political interest. Sadly, among those actively involved beyond going to the polls (e.g. Electoral Officers and Party Agents), a greater percentage of them are propelled by the financial gains as earlier observed by Eyo [11]. Our position therefore is that the participation or non-participation of individuals in Nigerian politics is a function of moral confusion whereby the elector is unable to decipher right from wrong but depends on real or imagined hunger and or resource-backed signals from others to act. In other words, the question of democratic participation is more reliant on moral self-identity in a predominantly resource-driven and corrupt political arrangement that thrives on the attendant low quality of life among the populace [12].

\section{Social Cognitive Theory: Theoretical frame work}

Bandura's [13] agentic socio-cognitive perception is that 'people are self-organizing, proactive, self-reflecting and self-regulating, and not just reactive organisms shaped and shepherded by external events'. The capacity to exercise control over one's thought processes, motivation, effects, and actions employs mechanisms of personal agency which build on the ethical moral-self. Narvaez [14] in Lapsley [15] argued that moral personality is best understood in terms of the chronic accessibility of morally-relevant schemas for constructing social events. A moral person in this regard is one for whom moral constructs as determined by parental instructs and religious injunctions are chronically accessible and easily activated by contextual clues. Consequently, highly accessible moral schemas provide a dispositional readiness to discern the moral dimensions of experience, as well as to underwrite the discriminative facility in selecting situation-appropriate behavior.

Aquino and Reed [16] opine that a person's moral identity as compassionate, fair, kind, honest, and so forth, is a schema consisting of a network of moral trait associations that is stored in memory as a complex knowledge structure. Individuals whose moral identity occupies greater centrality within the self-concept should perceive that being a moral person is more selfdefining than other identities in our working selfconcept either as Professors, Spouses, Sons, and so forth. Bryan, Adams and Monin [17] found strong relationship between moral identity and moral behavior. Moral identity influences the service and political involvement of adolescents [18] and provides an interpretive lens for appraising the honesty of leaders [19]. Individuals with strong moral identity are more empathic [20] less aggressive [21] and less likely to engage in organizational deviance [22] and unethical behavior at work [23].

With the extent of corruption in Nigeria's political landscape, one may wonder how moral identity influences partisn political participation. Previous research [24-26] demonstrates the damaging effect of corruption on citizens' attitudes towards the democratic and political process, as such the idea of corruption having an impact on political behaviour in terms of participation is not far-fetched. However, research on the effects of moral identity on political participation in a corrupt political system is scarce and constitutes a relatively new line of inquiry.

Review of researches on the effects of corruption on political participation offer mixed results but indicate that there are two competing views on the expected relationship and findings. The minority view is represented by scholars pursuing the argument of corruption as a mobilizing factor. The argument is straightforward; corruption is believed to create enraged citizens which in turn increases their willingness to punish corrupt politicians through participation. In line with this view, Johnston [27] reports a positive relationship between corruption and voter turnout in U.S presidential elections. Imman and Andrews [28] offer some empirical evidence for this position in Senegal. They found that perceptions of corruption increase the likeliness of both protesting and voting. In a study of Portuguese municipalities, Stockemer and 
Calca [29] found corruption to be a strong mobilizing factor, whereby high corruption areas display high voter turnout. Thus, the case has been made for the claim that corruption is a mobilizing factor.

The most adherent view held by scholars [30, $26,25]$ does however, claim a negative relationship between corruption and political participation. Here, corruption is believed to decrease citizens' willingness to engage in the political process and thus has a demobilizing effect. So far, three macro-level studies have been conducted. In a broad sample of democratic states, Stockemer, LaMontagne and Scruggs [31] found a negative relationship between corruption and voter turnout in legislative elections. Simpser [32] concluded that the belief of an election being corrupt decreases the likelihood of voting while Stockemer [25] also found a negative relationship between political corruption and voter turnout in a macro-level study covering 70 presidential elections. Notably, all three macro-level studies on the effects of corruption have only looked into voter turnout yet a lacuna still exists on research findings allowing for stronger generalizations on other types of political participation.

Dahlberg and Solevid [33] examined a large sample of countries, and found that voter turnout is lower when individuals perceive corruption as widespread. When controlling for system-level corruption in countries, the effects disappear where there are high levels of system-level corruption. Rothstein and Solevid [34] found a similar interaction effect on non-institutionalized participation, when examining perceptions of bureaucratic impartiality and system-level quality of government indicators. In a sample of Eastern European countries, Kostadinova [26] found a two-fold pattern. First, corruption might mobilize citizens who vote in order to throw the rascals out. However, the long-term effect of corruption on attitudes such as distrust in the democratic process, and perceived ability to actually influence politics, leads to the reversed reaction where citizens abstain their vote. The mobilizing effect is therefore cancelled in the long run. Besides, corruption also affects citizens' political efficacy, by weakening their beliefs in the potentials of their votes to make a difference. Kostadinova [26] concluded that corruption has a direct effect on turnout and an indirect effect of lowering individuals' sense of efficacy.

Voter turnout has been the primary object of interest, although some attention is being directed towards other types of participation. Notably, the literature suffers from a lack of explanatory focus, where few mechanisms behind the perceived relationships are put forward therefore pointing to the need to specify causal mechanisms and empirical accumulation. In the context of institutionalized corruption as evidenced in Nigeria [10], we propose that specifying the causal mechanisms between corruption and political engagement should start with examining possible relationships between partisan political participation and other plausible moderating variables.

Our study therefore specifically examines the possibility that causal mechanisms influence the quality and context of partisan political participation. We hypothesize that: Ethical moral-self would correlate significantly with partisan political participation.

\section{METHOD \\ Participants}

Three hundred and sixteen (316) residents of Enugu metropolis in the South-east of Nigeria participated in the study. Participants comprised 167 males and 149 females who had memberships in one of the registered political parties in Nigeria, and who were within the age range of 18 and 70 years. The mean age of the participants is 48.7 years.

\section{Instrument}

Two instruments were used to design the questionnaire for data collection - the Ethical MoralSelf Inventory (EMSI) and the Political Participation Scale (PPS). The Ethical-moral Self Inventory is one of the five scales in the Tennessee Self Concept Scale (TSCS) [35]. EMSI consists of the 18 Moral-Ethical Scale items and 10 Self-criticism items of the TSCS on a 5-point response scale ranging from "Completely false" $=1$ to "Completely True" $=5$. EMSI has been developed into an independent inventory by Omoluabi [36] owing to the increasing significance of morality in Nigerian clinical and social research. Morality, in the context of this scale, is conceptualized as the tendency of an individual to adopt the principles of fairness, equity, integrity, justice in guiding his or her behaviour in social interactions. The ethico-morality concept therefore covers more grounds than adopting the principle of right and wrong to evaluate social situations. The self-criticism scale (SCS) is the validity scale of the TSCS. The test-retest reliability coefficients obtained for the full TSCS test of which EMSI is a subscale are: .92 by Fitts [35] and .74 by Ezeilo [37]. Olukoya [38] obtained a concurrent validity coefficient of -.15 by correlating EMSI with Index of Self-Esteem (Hudson, 1982).

The Political Participation Scale (PPS) is a modified version of the Job Involvement Scale (JIS) developed by Lodahl and Kejner [39]. The original scale (JIS) consists of 18 -items; the response format range from "strongly agree" to "strongly disagree". The coding also ranged from 1 to 5 respectively. Ejiogu [40] adopted and validated the original scale in Nigeria with a split half reliability of .76 . In adaption the scale for use in the present study, five lecturers from 3 Universities in Nigeria examined the face and content validity of the original scale in terms of measuring partisan political participation. In the process, the word 
"work" was replaced with "political activities" in items 1, 5 and 8; "my work/job" were replaced with "politics" in items $3,4,7,9,12,13,14$ while items $2,10,11,16$ and 18 were deleted. In all, the scale was left with 13 items to measure political participation. Some of the item read: "I would probably keep engaging in partisan politics even if I did not need the money"; "Sometimes I lie awake at night thinking ahead to the next day's political activity"; "Quite often I feel like staying home from political party activity instead of coming in". All the lecturers certified the face and content validity of the scale as modified to measure political participation. The reliability of the scale was obtained through the test-retest reliability method using two-week interval responses of 60 Civil Servants drawn from 6 Stateowned Ministries in South-east Nigeria. The result of the test-retest yielded a high correlation coefficient of 65 .

\section{Procedure}

The respondents were drawn by purpose sampling carried out in various churches, market premises, offices, schools and universities on work days, during work hours. A total of four hundred (400) copies of the questionnaires were distributed. The survey which lasted for 14 days, gave each participant interval of 24 hours to return the filled questionnaire instruments. 84 questionnaires were invalidated: 29 for not being properly filled, and 55 for not have been returned, leaving us with 316 participants for data analysis (79\% return).

\section{Design/Statistics}

The study employed a survey design with data collection involving the use of questionnaires. The Pearson Correlation ( $r$ ) was used for data analysis in order to test the study hypothesis.

\section{RESULTS}

Table-1: Correlation of Ethical Moral Self and Partisan political participation

\begin{tabular}{|l|l|l|c|}
\hline & & Partisan political participation & Ethical Moral Self \\
\hline Partisan political participation & Pearson Correlation & 1 & $-.118^{*}$ \\
\hline Ethical Moral Self & Pearson Correlation & $-.118^{*}$ & 1 \\
\hline
\end{tabular}

Result of correlation in Table-1 above indicates significant negative relationship between the ethical moral-self and partisan political participation, $\mathrm{p}<$ .05. This means that there is a strong connection between moral identity and political engagement. Hence, the hypothesis of this study is accepted.

\section{DISCUSSION}

The result of the study indicates significant negative relationship between ethical moral self and partisan political participation. Thus, the hypothesis was accepted. This means that as the ethical moral-self improves, partisan political participation decreases and as partisan political participation increases, the ethical moral-self becomes poorer. This result is similar to Bryan et al., [17] who found a strong relationship between moral identity and moral behavior, and Porter's [18] findings that moral identity influences the service and political involvement of adolescents. An examination of the means showed that participants with poor ethical moral-selves were more involved in political activities. This indicates a tendency for people who consider themselves less decent to be more engaged in politics.

The results of this study prove that:

- The citizens who thought themselves to be righteous tend to distance themselves from political engagement.

- Those who engage in partisan politics tend to abandon good morals and ethical identity since they perceive politics as an opportunity to express the beast in them.

- An involvement in partisan politics in Nigeria can deteriorate one's sense of moral identity in reaction to the strong inundations with corruption and electoral malpractices [10].

The practice and influence of money politics has paved the way for the emergence of die-hard corner-cutting political participants influenced by varying forms of partisanship [41]. In other words, those who assess themselves as 'heaven's' candidates tend to avoid the political fray. This reinforces administrative recklessness among public officers and increases the likelihood of more dubious people engaging in politics. This paves the way for injustice, lack of regard for the welfare of the teeming populace [12], violation of human rights, social exclusivity and the emergence of individuals that are more powerful than institutions.

\section{IMPLICATIONS AND RECOMMENDATIONS}

The result of this study raises awareness of the imperative of responsible citizenship for good governance. They also portend implications of patriotic citizenship through grass-root policy formulation, adoption and implementation for engendering improved quality of life [12]. This is in tandem with the focus of the United Nations Sustainable Development Goal Sixteen which promotes peaceful and inclusive societies, provides access to justice for all and builds effective, accountable and inclusive institutions at all levels to ensure the sustainability of development. 
The responsibility of the government at all levels, civil society organizations and international organizations as stakeholders is to undertake sensitization programs to enhance citizen involvement and engagement in the governance and administrative processes in Nigeria. Citizens must be enlightened on their roles as stakeholders, the imperative of the ethical moral-self in redefining the quality of their involvement in the political processes and redesigning the political landscape in which they must engage, the potency of their rights and votes in the determination of the occupants of public offices and the implications of these for the posterity of the nation. The government in the exercise of its overarching functions must institute measures that instill the principle of accountability for public office. On the other hand, it must create a sustainable, inclusive, equitable, justiciable and enabling environment, cognizant of the interests of the competing groups in society and devoid of gender and ethno-religious affiliations.

\section{CONCLUSION}

This study examined the correlation between the ethical moral-self and partisan political participation. The results of the study indicate a significant influence of the former on the latter. We reiterate therefore that a better Nigeria depends on conscientious citizen involvement in the exercise of their franchises and the determination of the trajectory of political processes.

\section{REFERENCES}

1. Verba S, Nie NH, Kim JO. Participation and political equality: A seven-nation comparison. Cambridge: Cambridge University Press. 1978.

2. Lamprianou I. Contemporary Political Participation Research: A Critical Assessment. In K. N. Demetriou (Ed.) Democracy in Transition. Berlin Heidelberg: Springer. 2013. Retrieved on 21th October, 2017 from www.springer.com/

3. O'Toole T, Marsh D, Jones S. Political literacy cuts both ways: The politics of nonparticipation among young people. The Political Quarterly, 2003; 74(3), 349-360.

4. Bourne PA. Unconventional political participation in a middle-income developing country. Current Research Journal of Social Sciences, 2010; 2(2):196-203.

5. Marsh A. Political action in Europe and the USA. London: Macmillan. 1990.

6. Warren ME. The meaning of corruption in democracies. In Heywood PM. (Ed.) The Routledge International Handbook of Political Corruption. Albington: Routledge. 2013.

7. Thompson D. Mediated Corruption: The Case of the Keating Five. American Political Science Review, 1993; 87(2): 269-81. Retrieved on $16^{\text {th }}$ December, 2017 from www.mishkenot.org.il/
8. Verba S, Schlozman KL, Brady H. Voice and equality. Civic voluntarism in American politics. Cambridge: Harvard University Press. 1995.

9. Olsson SA. Corruption and Political Participation: A Multilevel Analysis. Working paper series, Department of Political Science, University of Gothenburg. 2014. Retrieved on 20 November, 2017 from https://www.qog.pol.gu.se/digitalAssets/

10. Lucky OO. Money politics and vote buying in Nigeria: the bane of good governance. Afro Asian Journal of Social Sciences, 4(4):3 Quarter III. 2013. Retrieved on 20/12/2017 from www.onlineresearchjournals.com/aajoss/art/116.p df

11. Eyo IE. Misperception: The psychological bane of Nigerian politics. In Ozioko JOC, Onuoha JI. (Eds.). Contemporary Issues in Social Sciences, 87-92. Nsukka: Topmost Publishers. 2002.

12. Allen AA. Population dynamics and infrastructure: meeting the millennium development goals in Ondo State, Nigeria. African Population Studies, 2013;27(2):229-237. http://aps.journals.ac.za

13. Bandura A. Social cognitive theory: An agentic perspective. Annual review of psychology, 52, 126. Palo Alto: Annual Reviews, Inc. 2001.

14. Narvaez D. Neurobiology and the development of human morality: Evolution, culture and wisdom. New York: Norton. 2014.

15. Lapsley D. Moral Self-Identity and the SocialCognitive Theory of Virtue. In Annas J, Narvaez D, Snow NE. (Eds). Developing the Virtues: Integrating Perspectives. New York. Oxford University Press. 2016. https://maplab.nd.edu/

16. Aquino K, Reed AII. The self-importance of moral identity. Journal of Personality and Social Psychology, 2002; 83:1423-1440.

17. Bryan CJ, Adams GS, Monin B. When cheating would make you a cheater: Implicating the self prevents unethical behavior. Journal of Experimental Psychology: General, 2013; 142, 1001-1005.

18. Porter TJ. Moral and political identity and civic involvement in adolescents. Journal of Moral Education, 2013; 42:239-255.

19. Grover SL. Moral identity as a lens for interpreting honesty of indirect leaders. Journal of Change Management, 2014; 14, 48-65.

20. Detert JR, Trevino LK, Sweitzer VL. Moral disengagement in ethical decision making: a study of antecedents and outcomes. Journal of Applied Psychology, 2008; 93, 374-391.

21. Barriga AQ, Morrison EM, Liau, AK, Gibbs JC. Moral cognition: Exploring the gender differences in antisocial behavior. Merrill Palmer Quarterly, 47, 532-562.

22. Greenbaum RL, Mawritz MB, Mayer DM, Priesemuth M. To act, to withdraw or to constructively resist? Employee reactions to 
supervisor abuse of customers and the moderating role of employee moral identity. Human Relations, 2013; 66, 925-950.

23. May DR, Chang YK, Shao R. Does ethical membership matter? Moral identification and its organizational implications. Journal of Applied Psychology, 2015; 100, 681-694.

24. Bauhr M, Grimes M. Indignation or Resignation: The Implications of Transparency for Societal Accountability. Governance, 2014; 27(2): 291320.

25. Stockemer D. Corruption and Turnout in Presidential Elections - A Macro-level Quantitative Analysis. Politics and Policy, 2013; 41(2):191-214.

26. Kostadinova T. Abstain or Rebel: Corruption Perceptions and Voting in East European Elections. Politics and Policy, 2009; 37(4):691714.

27. Johnston M. Corruption and Political Culture in America. Publius, 1983; 13(1):19-39.

28. Inman K, Andrews J. Political participation in Africa: evidence from survey and experimental research. Paper presented at the annual meeting of the Midwest Political Science Association. Chicago, IL, 2010 April; 22-25.

29. Stockemer D, Calca P. Corruption and turnout in Portugal - municipal level study. Crime, Law and Social Change, 2013; 60(5):535-548.

30. Dominguez JI, McCann JA. Mexicans React to Electoral Fraud and Political Corruption. Electoral Studies, 1998; 17(4):483-503.

31. Stockemer D, LaMontagne B, Scruggs L. Bribes and Ballots: The Impact of Corruption on Voter Turnout in Democracies. International Political Science Review, 2013; 34(1):70-92. Retrieved on $16^{\text {th }} \quad$ December, 2017 from http://journals.sagepub.com/
32. Simpser A. Making Votes not Count: Strategic Incentives for Electoral Corruption. $\mathrm{PhD}$ dissertation. Stanford, CA: Stanford University. 2004. www.ibrarian.net/

33. Dahlberg S, Solevid M. Does Corruption Supress Voter Turnout? A Multi-level Approach. In: Stepping Stones, Research on Political Representation, Voting Behaviour and Quality of Government. Gothenburg University, Department of Political Science. 2013.

34. Rothstein B, Solevid M. Perceptions of Corruption and Political Participation. Paper presented at Annual Conference of Midwest Political Science Association, Chicago, 2013; April 11-14.

35. Fitts PM, Biederman I. SR compatibility and information reduction. Journal of Experimental Psychology. 1965 Apr;69(4):408.

36. Omoluabi PF. Ethical Moral Self Inventory Manual. Department of Psychology, University of Lagos. 1999.

37. Ezeilo BN. Cross-cultural utility of the Tennessee self-concept scale. Psychological Reports. 1982 Dec;51(3):897-8.

38. Olukoya A. New approach to reproductive health in Nigeria. Nigerian Tribune, Tuesday 16th June. 1998.

39. Lodahl TM, Kejner M. The Definition and Measurement of Job Involvement. Journal of Applied Psychology, 1965; 49, 24-33.

40. Ejiogu KC. Reward Preference, Marital Status and Sex as Predictors of job Involvement. Unpublished M.sc Thesis University of Nigeria, Nsukka. 1986.

41. Erdmann G. Ethnicity, Voter Alignment and Political Party Affiliation: an African Case. Zambia (March 1), GIGA Working Paper No. 45. 2007. Available at SSRN: http://dx.doi.org/10.2139/ssrn.978175. 